\title{
Los mecanismos alternativos de solución de controversias en materia penal en México y su realidad
}

\author{
Alternative mechanisms for dispute resolution \\ in criminal matters in Mexico and its reality
}

\section{Amalia Patricia Cobos Campos ${ }^{1}$}

Universidad Autónoma de Chihuahua/México

pcobos@uach.mx

https://orcid.org/0000-0002-1979-3771

\begin{abstract}
Resumen: El proceso penal en México ha sufrido una metamorfosis toral, transformándose a un sistema de justicia penal acusatorio, modificación que se fue gestando por el alto grado de inconformidad de los mexicanos con la impartición de justicia. Derivado de ello se consagran constitucionalmente importantes innovaciones. Dentro de ese marco de modificación, en el artículo 17 de la carta fundamental, se establece la obligación de legislar en materia de mecanismos alternos de solución de controversias, por lo que no es de extrañar que el ordenamiento procesal penal de aplicación en toda la república, como lo es el Código Nacional de Procedimientos Penales los prevea. El presente artículo parte de la relevancia de tales mecanismos como una forma de eficientar la impartición de justicia y examina los me-
\end{abstract}

1 Doctora en Derecho con mención cum laude; Maestría en Ciencias Penales, Maestría en Derecho Financiero, Licenciatura en Derecho; Miembro del Sistema Nacional de Investigadores Nivel I; Profesora investigadora de la Facultad de Derecho de la Universidad Autónoma de Chihuahua, 29 años de antigüedad docente, impartiendo clases en licenciatura, maestría y doctorado; Premio Nuevo León a la Investigación Jurídica, 2014; Premio Ciencia, tecnología e innovación del gobierno de Chihuahua 2015; Medalla al mérito ciudadano Benito Juárez, 2016; Estancias posdoctorales de investigación en las universidades de Salamanca, Alcalá de Henares, Barcelona, Universidad de Texas en Austin, Universidad de Matto Grosso do Sul en Brasil. 
canismos existentes en dicho país, su construcción doctrinaria y su factibilidad para los efectos pretendidos, para ello se sustenta de la hermenéutica y la epistemología jurídicas, y como principal técnica de apoyo la revisión de literatura, lo anterior a efecto de dilucidar las particularidades de dichos mecanismos desde las perspectivas legislativa, jurisprudencial y doctrinaria en la búsqueda de demostrar si los esfuerzos del propio sistema de justicia para su implementación, resultan suficientes para minimizar las deficiencias que merman su eficacia.

PALABRAS CLAVE: reforma penal; proceso penal; mecanismos alternos.

ABSTRACT: The criminal process in Mexico has undergone a metamorphosis, becoming adversarial system of criminal justice, modification that was brewing for the high degree of dissatisfaction to the Mexicans with the delivery of Justice. Derived from these constitutionally reform, important innovations were created. Within this context of modification, in article 17 of the Constitution, establishing the obligation to legislate in the field of alternative dispute resolution mechanisms, so it is not surprising that the criminal procedural system of application in all the country, such as the national code of criminal procedure provides for them. This paper part of the relevance of such mechanisms as a way to streamline the delivery of Justice and examines the existing mechanisms in this country, its scholar construction and its feasibility for the intended purposes. It is furtherance from the epistemology and hermeneutic legal methods, and as the main technique of supporting the review of literature. The above effect of elucidating the particularities of these mechanisms from legislative, jurisprudential and doctrinal perspectives epistemology and Hermeneutics we looking conclude if the essential efforts of the system of Justice for its implementation, are sufficient to minimize some shortcomings that reduce its effectiveness.

KEYWORDS: criminal reform; criminal proceedings; alternative mechanisms.

SUMARIO: Introducción; I. Una implementación controversial; II. Marco legislativo de los medios alternativos de solución de controversias en el proceso penal en México; III. Realidad mexicana en materia penal; Consideraciones finales; Referencias. 


\title{
INTRODUCCIÓN
}

El mundo actual vive un proceso de incremento de la delincuencia e impunidad sin precedentes, lo que ha gestado en los estados contemporáneos una constante preocupación por eficientar la aplicación de la ley y frenar la impunidad; derivado de lo anterior se puede con concluir como lo hace Lander ${ }^{2}$ en alusión a ello que:

\begin{abstract}
"Junto al aumento del delito creció la alarma social, con frecuencia multiplicada por los medios de comunicaciones de masas. Ha habido también un endurecimiento de las leyes penales, procesales y sustantivas y la justicia penal reaccionó multiplicando el encierro. El resultado de todo ello se refleja en el crecimiento acelerado de las tasas de encierro, con su consiguiente sobrepoblación penitenciaria y resultado de homicidios y suicidios intracarcelarios y toda clase de violaciones a derechos humanos que ocurren, paradójicamente, como resultado del accionar del mismo sistema de justicia penal que tiene por función sancionar los delitos, (y eventualmente prevenirlos, si aceptamos como una de sus funciones la de prevención general de la criminalidad). (...) Como se puede ver, entre los años 1992-2008 los países de América Latina elevaron notablemente sus tasas de encierro, algunos de manera impresionante. Muchos duplicaron o más que duplicaron sus tasas (Argentina, Colombia, Costa Rica, Chile, El Salvador, México, Panamá, Perú, Uruguay) o estuvieron muy cerca de hacerlo (Ecuador, Nicaragua); Brasil triplicó su tasa; Argentina, El Salvador y Uruguay están próximos a triplicarlas. Resulta sencillo dilucidar que se trata de un problema que afecta a muchos estados y que ello ha llevado a incentivar cambios trascendentales en sus sistemas jurídicos”.
\end{abstract}

El presente trabajo se centra en México, por lo que no abordaremos los países Latinoamericanos restantes sin dejar de reconocer que un estudio comparado de la materia en estudio pudiera resultar interesante en una futura publicación; la respuesta de este país al incremento de la delincuencia y la impunidad fue una reforma toral que trastocó el sistema penal tradicional.

2 LANDER, Adriana (Coord.). Las reformas al sistema de justicia penal en Japón $y$ en América Latina, Logros, problemas, y perspectiva, Instituto Latinoamericano de las Naciones Unidas para la Prevención del Delito y el Tratamiento del Delincuente, Costa Rica: ILANUD, 2011, p.10. 
Son innumerables las publicaciones surgidas a partir del 2008 que analizan la referida transformación procesal acaecida en México, examinando sus alcances y consecuencias. Indudablemente que dejar atrás el sistema inquisitorio constituyó un paso importante para nuestro sistema jurídico, pese a las deficiencias que se han venido señalando en esta transformación por la abundante literatura existente y en las que no abundaremos por ser ajenas al propósito del presente estudio, en el que nos centraremos en principio en los antecedentes y marco conceptual de los mecanismos alternativos de solución de controversias, los cuales surgen como una disyuntiva a las deficiencias e insuficiencia del poder judicial para resolver todos los conflictos, y en ese contexto analizar su regulación en México, su construcción jurisprudencial y su eficacia fáctica en los subsecuentes apartados.

En principio, debemos diferenciar los métodos utilizados en estos mecanismos, que se centran en el arbitraje, la conciliación y en la mediación, siendo estos últimos los que privilegian todos los ordenamientos en la materia. Empero, debemos reconocer que el surgimiento de ellos se da en principio en el arbitraje, consagrado esencialmente en materia mercantil y fortaleciéndose en el comercio internacional, para posteriormente empezar a incidir en otras áreas del derecho, incrementando así su relevancia e impacto en los diversos procesos incluido el ámbito penal.

Es pertinente aclarar, como lo hace González de Cossío, ${ }^{3}$ que algunos autores utilizan conciliación y mediación como sinónimos y existe dificultad para precisar una naturaleza jurídica unánime de estas figuras. Sin embargo, la mayoría de la doctrina en el ramo en estudio considera que existen diferencias entre ambas figuras, así podemos discurrir a la conciliación como "un mecanismo de resolución de conflictos, a través del cual, dos o más partes someten una controversia ante un tercero neutral, el conciliador, quien conducirá y colaborará en la resolución de la controversia”, ${ }^{4}$ la mediación por su parte constituye un trámite en el cual el mediador como su nombre lo indica, solo interviene para facilitar

3 GONZÁLEZ DE COSSÍO, Francisco. Mecanismos alternativos de solución de controversias: Nota sobre el creciente desarrollo del área, Ars Iuris, no. 30, p. 39- 67, 2003.

4 Defensoría del Pueblo. Guía básica de derechos mediación, conciliación y arbitraje. 
el diálogo entre las partes en controversia, ambos a fin de cuentas son vías de solución de que se valen los mecanismos alternativos de solución de controversias.

Como decíamos en párrafos anteriores la naturaleza de los medios materia de nuestro estudio, popularmente conocidos por el acrónimo de su nombre como MASC (o ACRMs por sus siglas en inglés), es discutida por la doctrina por lo que cabe plantearnos la pregunta $i^{\text {son }}$ medios de autocomposición o de heterocomposición?

Para dilucidar una respuesta adecuada tendremos en principio que conceptuar ambas figuras jurídicas, los primeros integrados por dos vocablos latinos auto y el sustantivo compositio "que dentro de la concepción carneluttiana equivale a solución, resolución o decisión del litigio [...] obtenida por obra de los litigantes, a diferencia de la que tras el proceso decreta el juez", ${ }^{5}$ asimismo, Alcalá-Zamora ${ }^{6}$ alude a una actitud que denomina altruista ${ }^{7}$ ya que mediante esta figura jurídica las partes asumen una posición de renuncia o reconocimiento según sea el caso; sin embargo, el precitado autor hace énfasis en la problemática de esta figura que puede llevar a ahondar los desequilibrios procesales. La autocomposición puede realizarse mediante tres diligencias distintas, cuyos efectos son igualmente diversos en el proceso y son el allanamiento, el desistimiento y la transacción.

Es relevante establecer que esta figura se puede dar de manera unilateral o bilateral y que como apunta el mencionado jurista la autocomposición no puede darse sin el poder de disposición del litigio y, en consecuencia, cuando hablamos de derechos de los que las partes no pueden disponer o indisponibles y cuando se requiere la intervención del juzgador para tales renuncias, no puede actualizarse y será menester acudir a otras figuras jurídicas, por lo que deberemos concluir que los medios en estudio no podemos ubicarlos como instrumentos de la autocomposición de manera lisa y llana particularmente en el proceso penal

5 Véase: ALCALÁ-ZAMORA Y CASTILLO, Niceto. Proceso autocomposición y defensa: Contribución al estudio de los fines del proceso, 3a ed., México: UNAM, 2000, p. 77.

6 Ibídem, p. 78.

7 Cursivas en el original 
que es el que nos interesa analizar, no obstante hay autores como Vado Grajales $^{8}$ que los consideran parte de ellos.

La heterocomposición a diferencia de la antes analizada, es considerada por la doctrina jurídica como una solución dada al litigio por un tercero ajeno al problema y que lo resuelve de manera vinculativa. ${ }^{9}$

Así se visualiza a los medios alternativos como "procedimientos mediante los cuales las personas puedan resolver sus controversias sin necesidad de una intervención jurisdiccional", ${ }^{10}$ o como "mecanismos que han sido implementados [...] para ampliar el acceso a la justicia de diversos grupos de la población, ya sea mediante la provisión de servicios de asistencia o para dar respuesta a todas aquellas necesidades jurídicas (sea conflicto o no) por vías diversas al proceso judicial tradicional". ${ }^{11}$

Brown y Marriot ${ }^{12}$ por su parte, consideran que se trata de "una gama de procedimientos que sirven como alternativas a los procedimientos adjudicatorios de litigo y arbitraje, para la solución de controversias que por lo general, aunque no necesariamente, involucran la intercesión de un tercero neutral que ayuda a facilitar dicha solución".

Esta es una forma de modificar la justicia retributiva hacia lo que se ha denominado justicia restaurativa, transformando la concepción y finalidades de la justicia, en busca de la eficaz salvaguarda de los derechos de la víctima y la restitución de los mismos en su caso.

Pali $^{13}$ al respecto, estima que la justicia restaurativa es;

8 Véase: VADO GRAJALES, Luis Octavio. Medios alternativos de solución de conflictos. En CIENFUEGOS, David y MACÍAS VÁSQUEZ María del Carmen (Coord.), Estudios en homenaje a Marcia Muñoz de Alba Medrano. México: UNAM, 2006. pp. 369-389.

9 Ibíd., p. 375.

10 Ibíd., p. 377.

11 LILLO LOBOS, Ricardo; CABEZÓN PALOMINOS, Andrea; FANDIÑO CASTRO, Marco. Mecanismos alternativos al proceso judicial para favorecer el acceso a la justicia en América Latina.

12 Citados por: ESTAVILLO Castro, Fernando. "Medios alternativos de solución de controversias”, Jurídica, Anuario del Departamento de Derecho de la Universidad Iberoamericana, México, n. 26, pp. 373-406, 1996.

13 PALI, Brunilda. "Active justice: Restorative justice processes as fertile ground for exercising citizenship”, Sistema Penal \& Violência Revista Eletrônica da Faculdade de Direito. Rio Grande do Sul: v. 6, n. I, p. 31-42, janeiro-junho 2014. 
[...] a reflective discourse of justice that emphasizes repairing the harm caused by crime, whereby crime is viewed more comprehensively than simply law breaking. Acknowledging that crime causes (material, social, psychological, and relational) harm to people and communities, restorative justice insists that justice repair those harms and that the parties be permitted to participate in that process - often in face to face meetings with the support of a mediator or facilitator. Restorative justice programmes, therefore, enable the victim, the offender and affected members of the community to be directly involved in responding to the crime.

Esta búsqueda de la justiciar restaurativa frente a la distributiva motivada por el incremento delincuencial y por la falta de credibilidad de los tribunales ante los ciudadanos nos lleva, como afirma Nóbrega de Abreu Campanário: ${ }^{14}$

Face a este fracasso do actual sistema de justiça criminal, com consequências particularmente visíveis ao nível do crescente sentimento de insegurança - potenciado pela projecção mediática dos processos mais sonantes, diariamente acompanhados pela média, são em abstracto configuráveis por dois caminhos alternativos: ou "mais do mesmo", isto é, ou se apetrecha o actual sistema de mais meios humanos e materiais, aumentando-se o número de tribunais, de magistrados, de prisões e, eventualmente, se agravam as penas, ou por outro lado, se desenvolvem e exploram novas ideias e modelos para lidar com o fenómeno da criminalidade. A denominada justiça restaurativa trilha este último caminho.4 Ela pretende possibilitar uma abordagem particular em caso de violência, viabilizando um diálogo entre vítima e agressor de forma a conferir-lhes voz e vez, objectivando o contrato com o conhecimento e o reconhecimento do dano ou erro, assim como a oportunidade de sua possível reparação.

Como es evidente, se articulan alternativas que dejan de lado el proceso judicial tradicional y se gestan bajo la premisa de resolver de manera más ágil y expedita las controversias entre los particulares.

14 NÓBREGA DE ABREU CAMPANÁRIO, Micaela Susana, "Mediação penal Inserção de meios alternativos de resolução de conflito", Civitas, v. 13, n. 1 (2013), p. 118-135. 
Estos mecanismos han sido impulsados en mayor medida a partir de 2008, en que en la Conferencia de Ministros de justicia de los países Iberoamericanos se hizo hincapié en la relevancia de aplicar dichos mecanismos para eficientar el acceso a la justicia de los grupos vulnerables, ${ }^{15} \mathrm{y}$ se ha ido fortaleciendo a través de compromisos asumidos en las respectivas conferencias anuales y bajo las premisas que se desprenden de los respectivos informes también de periodicidad anual. ${ }^{16}$

Son, en resumen, herramientas cuyo objetivo esencial se traduce en eficientar el acceso a la justicia descargando al aparato jurisdiccional de su usualmente excesiva carga que impide la expeditez de la justicia y permiten auxiliar a los ciudadanos a alcanzar de manera más expedita la reparación a la que pudieran tener derecho.

Un concepto muy amplio nos lo da Zepeda Leucona ${ }^{17}$ que los considera como "[...] la sistematización de técnicas para establecer las condiciones (como equidad comunicativa, seguridad, libertad e igualdad entre las partes) para que las partes de un conflicto, por sí mismas o con la participación de un facilitador neutral, construyan de manera voluntaria, libre y confidencial acuerdos que terminen con la situación conflictiva".

Su eficacia tal vez sea pronto para juzgarla, cuando menos en México, y en última instancia consideramos que dicha valoración deberá darse de manera diversificada según el medio alterno de que se trate, para medir desde distintos parámetros su incidencia real en el acceso a la justicia.

Por lo que a la materia penal respecta, en párrafos subsecuentes analizaremos los aspectos legislativos que los revisten, empero a diferencia de otras áreas del derecho el posible acuerdo de la salida alterna se centra en la reparación del daño a la víctima u ofendido.

15 XIV Cumbre Judicial Iberoamericana. Reglas de Brasilia sobre Acceso a la Justicia de las personas en condiciones de Vulnerabilidad, celebrada en Brasilia, del 4 al 6 de marzo de 2008.

16 Véase: Secretaría General Iberoamericana. Programa iberoamericano de acceso a la justicia.

17 ZEPEDA LEUCONA, Guillermo Raúl. Índice estatal de desempeño de las procuradurías y fiscalías. 


\section{UNA IMPLEMENTACIÓN CONTROVERSIAL}

Debemos partir de que al aludir a estos medios resulta esencial clarificar que existen inteligibles diferencias entre el derecho debatido y el procedimiento para declararlo, pues en el primero por razones evidentes, su titularidad pertenece indiscutiblemente a las partes, y en esa tesitura, los primeros son quienes tienen la facultad de decidir la forma en que quieran sea controvertido más no pueden imponer formas o figuras procesales propias sino que tendrán que someterse a las previstas en la respectiva legislación.

Hecha la anterior aclaración debemos igualmente decir que si bien se habla de lo novedoso de estas figuras como alternativas al proceso judicial realmente no lo es tanto porque modelos de conciliación y mediación han existido desde los orígenes del hombre, y encontramos antecedentes muy remotos en la regulación como es el caso de Portugal quien introdujo en el Código Manuelino de 1521 la conciliación como prerrequisito para la admisión de la demanda ${ }^{18}$; su novedad en caso dado lo es su formalización legislativa en un sentido que busca facilitar el acceso a la justicia de los particulares y su claro enfoque hacia la voluntariedad en su utilización.

Uno de los puntos controversiales al respecto en su implementación lo constituye sin duda es su establecimiento con carácter obligatorio como una etapa prejudicial forzosa, como ocurrió en el ya mencionado caso de Portugal y con la mediación prejudicial obligatoria en Argentina y la de conciliación extrajudicial en Colombia; cuestiones que fueran puestas en tela de juicio, visto el carácter voluntario que la doctrina le adjudica como una de sus características inherentes ${ }^{19}$.

En vista de ello se habló de la ausencia de voluntariedad, que como ya se dijo es el elemento base de estos mecanismos, por lo que igualmente

18 Véase: VÁSQUEZ SANTAMARÍA, Jorge Eduardo; LEZCANO MIRANDA, Martha Eugenia. The alternative methods of conflict resolution: some improvement challenges for justice in Colombia. In MOKRYS, Michal; BADURA, Stefan (editores). Proceedings in Human and Social Sciences at the Common Conference. Zilina: EDIS, 2017, pp. 32-37.

19 LILO Lobos, Ricardo, CABEZÓN Palominos, Andrea y FANDIÑO Castro, Marco, óp. Cit., p. 22. 
se debate si se trata de sustituir a la justicia o tan sólo son mecanismos adicionales o auxiliares de esta y, en qué forma abate la seguridad jurídica.

Estos aspectos deben examinarse para no caer en el primer supuesto, toda vez que su finalidad esencial es claro que se enfoca al auxilio de la administración de justicia y no a una sustitución o privatización de la misma, al respecto Vivero de Porras considera que:

Por tanto, necesitamos saber que la oferta en justicia debe perseguir como objetivos minimizar costes y maximizar servicios. Dadas las tasas de pendencia señaladas y las ratios de asuntos, la actual configuración de nuestro sistema puede catalogarse (por muchas razones) de todo menos de eficiente. Las razones [...] se centran en la gestión y en las estructuras existentes: dispersión, duplicación en la descentralización, insuficiencia de recursos, sistemas arcaicos de administración, cultura social, etc. Todo ello conlleva la necesidad -junto a la reforma legal- de una reestructuración que conciba el ámbito judicial y las resoluciones alternativas de disputas como alternativas y quizás con el objetivo (ello es más dudoso dada la casuística que pueda haber) de que se trate de consumos de justicia sustitutivos perfectos para evitar duplicidades también en la utilización de los medios de heterocomposición que se ofrecen. ${ }^{20}$

Ante estas posturas debemos enfatizar que los mecanismos no deben encauzarse como sustitutivos de la justicia, ello en aras de la seguridad jurídica que representa un punto esencial cuya responsabilidad recae en el estado y nunca en los particulares, sean estos mediadores, árbitros o cualquiera que sea la denominación que se les asigne en los diversos mecanismos adoptados por los estados ya que no existe uniformidad en la denominación de los mismos.

Otro punto sin duda lo constituye el financiamiento de los multicitados MASC, ya que al prestarse en algunos casos por organismos ajenos al poder judicial y en ciertos países por mediadores particulares, es ineludible la necesidad de definir al respecto, lo que genera igualmente disensiones, dada la gratuidad del sistema judicial estatal; debiendo empero recordar que también existen costas en algunos procedimientos, no así en el penal.

20 VIVERO DE PORRAS, Carmen de. Medios alternativos de solución de conflictos. eXtoikos, no. 12, 2013. pp. 35-37. 
Son muchos los aspectos bajo los que se pone en tela de juicio la bondad de las figuras jurídicas materia de nuestro estudio, pero es válido decir que la mayoría de las legislaciones actuales las contemplan y han cifrado en ellas la posibilidad de una mayor y más equitativa accesibilidad de los justiciables a la restitución de sus derechos vulnerados.

\section{Marco legislativo de los medios alternativos de solución DE CONTROVERSIAS EN EL PROCESO PENAL EN MÉxICO}

En principio podemos hablar de una consagración constitucional expresa en el artículo 17 que en su párrafo quinto a la letra determina “[...] Las leyes preverán mecanismos alternativos de solución de controversias. En la materia penal regularán su aplicación, asegurarán la reparación del daño y establecerán los casos en los que se requerirá supervisión judicial [...]”.

Del tenor del precepto constitucional podemos extraer una serie de requisitos que la propia carta fundamental prevé expresamente para la materia penal, en principio alude a la reparación del daño, por lo que se evidencia el requerimiento del legislador de proteger a la víctima mediante dicha reparación, la cual a juicio de Esparza Martínez ${ }^{21}$ analizando el marco constitucional que tutela la misma, particularmente en el contenido de los artículos $1^{\circ}$, 17 y 20 del ordenamiento constitucional, considera que es regulada en lo relativo al proceso penal, bajo la premisa de tres directrices, la primera la concibe como una garantía a cargo del estado de reparar las violaciones a los derechos humanos, igualmente puede ser estimada en una segunda directriz como una vía jurisdiccional diversa a la que el autor en cita llama "tercera vía jurisdiccional" y, finalmente, como derecho de la víctima u ofendido.

De lo anterior dilucidamos que el sustento de la reparación lo es la propia constitución y a partir de ella, podemos entender sus alcances y contenido que es evidente se complementan con las leyes secundarias que la regulan, esencialmente en el caso de México en la Ley general de

${ }^{21}$ ESPARZA MARTÍNEZ, Bernardino. La reparación del daño. México: INACIPE, 2015. p. 6. 
Víctimas y el Código Nacional de Procedimientos Penales, y que puede ser percibida dentro de diversos contextos que la reglan.

La reparación del daño ha sufrido profundas transformaciones hasta llegar a su concepción de reparación integral la cual ha sido claramente delimitada por la Corte Interamericana de Derechos Humanos al establecer que comprende "[...] el reconocimiento de la dignidad de las víctimas, el consuelo de los derechos humanos de que se trata [...]”22, aludiendo igualmente a la reintegración y no repetición y a la reparación del daño al proyecto de vida de la víctima, el cual según la Corte "[...] atiende a la realización integral de la persona afectada, considerando su vocación, aptitudes, circunstancias, potencialidades $\mathrm{y}$ aspiraciones que le permiten fijarse razonablemente determinadas expectativas y acceder a ellas"23.

Derivado de lo anterior como afirma Calderón Gamboa:

A la fecha la Corte IDH ha emitido más de 155 sentencias de reparaciones con destino a 22 Estados miembros de la OEA. Si bien el cumplimiento y debida implementación de las reparaciones de la Corte IDH aún representa un desafío, cada vez se incrementa el efectivo cumplimiento por parte de los Estados, a través de la incorporación de diferentes mecanismos de implementación doméstica, alcanzando cambios sustanciales en sus sociedades, por lo que comprender y fortalecer este proceso beneficia a todo el SIDH y los procesos democráticos en la región."

Sin embargo, autores como Uprimny y Saffon ${ }^{24}$ han estimado que tal perspectiva restitutiva de la reparación integral "se queda corta, limitada, es poco realista y demasiado exigente cuando se pretende resarcir a individuos pertenecientes a sociedades que vivencian una profunda crisis

22 CORTE INTERAMERICANA DE DERECHOS HUMANOS, Caso Myrna Mack Chang vs Guatemala, Fondo, reparaciones y costas, Sentencia de 25 de noviembre de 2003, Serie C, No. 101, párr. 268.

23 CORTE INTERAMERICANA DE DERECHOS HUMANOS, Caso Loayza Tamayo vs Perú, Reparaciones y costas, Sentencia de 27 de noviembre de 1988 , Serie C, No. 42, párr. 147.

24 Citados por: NANCLARES MÁRQUEZ, Juliana; GÓMEZ GÓMEZ, Ariel Humberto. La reparación: una aproximación a su historia, presente y prospectiva. Civilizar ciencias sociales y humanas, Bogotá: v. 17, n. 33, pp. 59-79, 2017. 
política y humanitaria y, que ya estaban en condiciones de desigualdad antes de padecer el daño".

Aunado a que como afirma Hernández Pliego ${ }^{25}$ "en un número mayoritario de casos, al ofendido o a la víctima no le es reparado el daño ocasionado por el delito, ello a pesar de que en nuestro medio la reparación tiene el carácter de pena pública, siendo múltiples las razones o sin razones que en cada caso podrían darse, ocupando lugar prioritario desde luego, la insolvencia del inculpado que en nuestro país opera como regla general, si se piensa en que el $80 \%$ de la población carcelaria tiene nombrado al defensor público, por no tener las posibilidades económicas de contratar un abogado particular".

Así vemos que "[e]l índice de impunidad en México aumentó tanto en el ámbito global como en el de los estados de la República. México ocupa el cuarto lugar del Índice Global de Impunidad (IGI-2017) con 69.21 puntos (Croacia es el país con el menor índice con 36.01 y Filipinas tiene el puntaje más elevado con 75.6). México encabeza la lista de países del continente americano con el más alto índice de impunidad”. ${ }^{26}$

Luego entonces, ante un sistema que busca la reparación integral nos encontramos con una realidad que impide que esta se dé adecuadamente por cuestiones extraprocesales y que dependen de la capacidad económica o ausencia de ella en el inculpado, lo cual es atribuible a que en México nunca se ha cristalizado la existencia del fondo que para tal fin establece la propia Ley General de Víctimas y que han integrado muchos otros países bajo diferentes esquemas o denominaciones como verbigracia la caja de resarcimiento en Cuba que depende del Ministerio de Justicia de dicho país. ${ }^{27}$

Además del elemento de la reparación el texto constitucional en análisis alude a una supervisión que deberá ser regulada en los casos y

25 HERNÁNDEZ PLIEGO, Julio Antonio. La reparación del año en el CNPP. In: GARCÍA RAMÍREZ, Sergio; GONZÁLEZ MARISCAL, Olga (Coord.), El código nacional de procedimientos penales: Estudios. México: UNAM, 2015. pp. 239-254.

26 LE CLERQ ORTEGA, Juan Antonio; RODRÍGUEZ SÁNCHEZ LARA, Gerardo (Coord.). La impunidad subnacional en México y sus dimensiones IGI MEX 2018. Puebla: Universidad de las Américas, 2018. p. 7.

27 Ministerio de Justicia República de Cuba. Caja de Resarcimientos. 
bajo los supuestos que la ley ordinaria determine, por lo que debemos indudablemente analizar la legislación de esta índole que regula a los medios en estudio y que en México se centra en las ya apuntadas Ley General de Víctimas ${ }^{28}$, Código Nacional de Procedimientos Penales ${ }^{29} \mathrm{y}$ no de menor importancia la ley exprofeso que lo es la Ley Nacional de Mecanismos Alternativos de Solución de Controversias en materia Penal ${ }^{30}$.

En el contexto del primer ordenamiento mencionado, esto es, la Ley general de Víctimas, examinaremos lo que el mismo entiendo por víctima, lo cual está estipulado en el artículo cuarto que es del siguiente tenor:

\section{Artículo 4.}

Se denominarán víctimas directas aquellas personas físicas que hayan sufrido algún daño o menoscabo económico, físico, mental, emocional, o en general cualquiera puesta en peligro o lesión a sus bienes jurídicos o derechos como consecuencia de la comisión de un delito o violaciones a sus derechos humanos reconocidos en la Constitución y en los Tratados Internacionales de los que el Estado Mexicano sea Parte.

Son víctimas indirectas los familiares o aquellas personas físicas a cargo de la víctima directa que tengan una relación inmediata con ella.

Son víctimas potenciales las personas físicas cuya integridad física o derechos peligren por prestar asistencia a la víctima ya sea por impedir o detener la violación de derechos o la comisión de un delito.

La calidad de víctimas se adquiere con la acreditación del daño o menoscabo de los derechos en los términos establecidos en la presente Ley, con independencia de que se identifique, aprehenda, o condene al responsable del daño o de que la víctima participe en algún procedimiento judicial o administrativo.

\footnotetext{
28 Ley General de Víctimas. Diario Oficial de la Federación de 09 de enero de 2013.

29 Código Nacional de Procedimientos Penales. Diario Oficial de la Federación de 05 de marzo de 2014.

${ }^{30}$ Ley Nacional de Mecanismos Alternativos de Solución de Controversias en materia Penal. Diario Oficial de la Federación de 29 de diciembre de 2014.
} 
Son víctimas los grupos, comunidades u organizaciones sociales que hubieran sido afectadas en sus derechos, intereses o bienes jurídicos colectivos como resultado de la comisión de un delito o la violación de derechos.

El numeral parte del daño o menoscabo para determinar la calidad de víctima, sin embargo, la doctrina y los criterios de la corte consideran que el daño es un menoscabo patrimonial, así se desprende de la tesis que bajo el rubro "daño y perjuicio, diferencia entre (legislación del Distrito y Territorios Federales)"31 analiza estas figuras desde la perspectiva del derecho civil y asume el concepto de Escriche bajo el cual el daño es un perjuicio, detrimento o menoscabo, de donde inferimos que no se trata de vocablos sinónimos y que el daño siempre implica algún tipo de menoscabo.

Igualmente es obvio que hace referencia a patrimonio material e inmaterial y clasifica las víctimas en directas, indirectas y potenciales. Por lo que atañe a la reparación del daño, el ordenamiento alude a reparación integral y determina lo conducente en los numerales 26 y 27 que a la letra dicen:

Artículo 26.

Las víctimas tienen derecho a ser reparadas de manera oportuna, plena, diferenciada, transformadora, integral y efectiva por el daño que han sufrido como consecuencia del delito o hecho victimizante que las ha afectado o de las violaciones de derechos humanos que han sufrido, comprendiendo medidas de restitución, rehabilitación, compensación, satisfacción y medidas de no repetición ${ }^{32}$.

Los requerimientos de oportunidad, plenitud, diferenciación, transformación, integralidad y efectividad parecen establecer parámetros muy difíciles de alcanzar, en principio la oportunidad nos lleva a las cuestiones de expeditez respecto de las cuales ha existido tanto cuestionamiento hacia los operadores judiciales dada la permanente saturación en los tribunales.

\footnotetext{
31 Amparo directo 4809/66. Carlos Morales Saldívar y coagraviados. 20 de enero de 1967. Cinco votos. Ponente: Agustín Mercado Alarcón.

32 Ley General de Víctimas, óp. Cit., Artículo 26.
} 
La plenitud por su parte es un vocablo cuyo significado podría llevar a ambigüedades ya que en sentido literal proviene del vocablo latino plenitûdo, y significa según el Diccionario de la Lengua ${ }^{33}$, totalidad, integridad o cualidad de pleno y también apogeo, momento álgido o culminante de algo, en este caso valdría la pena analizar si se está abusando del uso de voces que a fin de cuentas se encaminan a los mismo, pues si se habla en términos generales de reparación integral debería obviarse el uso del término plenitud.

Artículo $27^{34}$.

Para los efectos de la presente Ley, la reparación integral comprenderá:

I. La restitución busca devolver a la víctima a la situación anterior a la comisión del delito o a la violación de sus derechos humanos;

II. La rehabilitación busca facilitar a la víctima hacer frente a los efectos sufridos por causa del hecho punible o de las violaciones de derechos humanos;

III. La compensación ha de otorgarse a la víctima de forma apropiada y proporcional a la gravedad del hecho punible cometido o de la violación de derechos humanos sufrida y teniendo en cuenta las circunstancias de cada caso. Ésta se otorgará por todos los perjuicios, sufrimientos y pérdidas económicamente evaluables que sean consecuencia del delito o de la violación de derechos humanos;

IV. La satisfacción busca reconocer y restablecer la dignidad de las víctimas;

V. Las medidas de no repetición buscan que el hecho punible o la violación de derechos sufrida por la víctima no vuelva a ocurrir;

VI. Para los efectos de la presente Ley, la reparación colectiva se entenderá como un derecho del que son titulares los grupos, comunidades u organizaciones sociales que hayan sido

33 Real Academia Española, Diccionario de la Lengua Española, voz: plenitud.

34 Ley General de Víctimas, óp. Cit., Artículo 27. 
afectadas por la violación de los derechos individuales de los miembros de los colectivos, o cuando el daño comporte un impacto colectivo. La restitución de los derechos afectados estará orientada a la reconstrucción del tejido social y cultural colectivo que reconozca la afectación en la capacidad institucional de garantizar el goce, la protección y la promoción de los derechos en las comunidades, grupos y pueblos afectados. Las medidas colectivas que deberán implementarse tenderán al reconocimiento y dignificación de los sujetos colectivos victimizados; la reconstrucción del proyecto de vida colectivo, y el tejido social y cultural; la recuperación psicosocial de las poblaciones y grupos afectados y la promoción de la reconciliación y la cultura de la protección y promoción de los derechos humanos en las comunidades y colectivos afectados.

Las medidas de reparación integral previstas en el presente artículo podrán cubrirse con cargo al Fondo o a los Fondos Estatales, según corresponda.

Igualmente es claro que el legislador mexicano se decanta por la reparación en los términos que a la misma atribuye la Corte Interamericana de Derechos Humanos, incorporando como ya se dijo de manera expresa el concepto de reparación integral a este ordenamiento y determinando de manera pormenorizada lo que comprende, es decir, restitución, rehabilitación, compensación, satisfacción como mecanismo para recuperar la dignidad y la no reiteración de la conducta lesiva. Asimismo, se plantean los supuestos de reparación colectiva para tutelar a determinados grupos por vulneración de derechos individuales o colectivos.

En cuanto al Código Nacional de Procedimientos Penales cuenta con el título primero bajo el rubro "Soluciones alternas y formas de terminación anticipada”, y en el numeral 184 establece como soluciones alternas del procedimiento a los acuerdos reparatorios y la suspensión condicional del proceso. El artículo 186, establece que los acuerdos reparatorios son "aquéllos celebrados entre la víctima u ofendido y el imputado que, una vez aprobados por el Ministerio Público o el Juez de control y cumplidos en sus términos, tienen como efecto la extinción de la acción penal”. ${ }^{5}$

35 Código Nacional de Procedimientos Penales, óp. Cit., Artículo 186. 
Igualmente, el precepto subsecuente limita la procedencia de dichos acuerdos a tres supuestos, el primero en el caso de delitos cuyo prerrequisito de procedibilidad es la querella o que admiten el perdón de la víctima u ofendido, el segundo es en el caso de delitos culposos y finalmente, respecto de delitos patrimoniales en cuya conducta comisiva no existió violencia hacia las personas.

El numeral en análisis excluye expresamente aquellos casos "en que el imputado haya celebrado anteriormente otros acuerdos por hechos que correspondan a los mismos delitos dolosos tampoco procederán cuando se trate de delitos de violencia familiar o sus equivalentes en las Entidades federativas"36. Y añade que "tampoco serán procedentes en caso de que el imputado haya incumplido previamente un acuerdo reparatorio, salvo que haya sido absuelto". ${ }^{37}$

La oportunidad procesal para realizar dichos acuerdos, en los términos del diverso precepto 188 del ordenamiento en mención, es desde la presentación de la denuncia o querella hasta antes de decretarse el auto de apertura a juicio; asimismo si se dictó el auto de vinculación a proceso las partes podrán solicitar al juez de control antes de que se haya dictado el auto de apertura a juicio, la suspensión del proceso penal hasta por treinta días para alcanzar el respectivo acuerdo.

De la misma forma, tanto el juez de control como el ministerio público están facultados por la ley en comento para "invitar a los interesados" a la celebración de dichos acuerdos, lo que se ha traducido en la práctica en una forma de presión hacia las víctimas para su realización.

Los acuerdos deben ser aprobados por el juez previo cercioramiento de que "las obligaciones que se contraen no resulten notoriamente desproporcionadas y que los intervinientes estuvieron en condiciones de igualdad para negociar y que no hayan actuado bajo condiciones de intimidación, amenaza o coacción" ${ }^{38}$

De igual manera la suspensión condicional del proceso requiere solicitud del imputado o el ministerio público en el que se deberá formular "un plan detallado" de la manera en que se realizará la reparación

\footnotetext{
36 Ibidem.

37 Ibidem.

38 Ídem, artículo 190.
} 
del daño, toda vez que esta figura procesal puede en su caso ser extintiva de la acción penal, ${ }^{39}$ deberá el imputado cumplir además una o varias de las condiciones que el mismo Código le impone en el numeral 195, con la finalidad de tutelar los derechos de la víctima u ofendido para poder originar la extinción de la acción penal. Dichas condiciones oscilan entre la permanencia en un lugar determinado hasta participar en programas especiales para el tratamiento de adicciones, condiciones que determinará el juez según en caso concreto y las medidas que considere idóneas para los fines antes apuntados.

La Ley Nacional de Mecanismos Alternativos de Solución de Controversias en materia Penal ${ }^{40}$, en su artículo tercero fracción novena, plasma como mecanismos alternativos a la mediación, la conciliación y la junta restaurativa, estableciéndose en el numeral 4 los principios rectores de dichos mecanismos, los cuales son siete, voluntariedad información confidencialidad, flexibilidad y simplicidad, imparcialidad, equidad y honestidad. ${ }^{41}$

En consecuencia, como se dijo en párrafos antecedentes no deben ser obligatorios sino partir de la voluntad de las partes expresada de manera oral o escrita, quienes deberán contar con la suficiente información para tomar una decisión equitativa orientada por un facilitador imparcial que apoyará al solicitante y al requerido como partes en los mecanismos para poder alcanzar un acuerdo apoyados por expertos en caso necesario y a solicitud de los intervinientes ${ }^{42}$.

El facilitador es personal adscrito a los órganos ${ }^{43}$ dependientes de las procuradurías, fiscalías o al poder judicial, por lo que no existe independencia de estos órganos respecto de los poderes del estado, así que se trata de una labor que no pueden desempeñar los particulares lo cual es explicable dada la naturaleza del proceso penal.

39 Ídem, artículo 191.

40 Ley Nacional de Mecanismos Alternativos de solución de controversias en materia Penal, óp. Cit.

41 Ídem.

42 Ibíd., artículos 3-19.

43 La Institución especializada en Mecanismos Alternativos de Solución de Controversias en materia penal de la Federación o de las entidades federativas. 
El procedimiento a seguir se puede simplificar en la presentación de la solicitud que debe ser aprobada por el aludido órgano y en caso de no ser procedente deberá establecer clara y fundadamente las razones por las que se rechaza dicha solicitud; aprobada por el órgano se procede a iniciar el expediente registrándolo y expresando una breve relación de los hechos materia del mismo, realizado lo cual se extenderá la invitación al sujeto procesal contrario al solicitante al que como ya se asentó en parágrafos antecedentes se le llama requerido. El facilitador puede realizar sesiones preliminares con las partes por separado si lo estima pertinente y a la sesión en la que intervienen todos se le llama conjunta y se puede realizar a través de la mediación o la conciliación.

La mediación la define la normatividad en estudio en su artículo 21 como el "mecanismo voluntario mediante el cual los Intervinientes, en libre ejercicio de su autonomía, buscan, construyen y proponen opciones de solución a la controversia, con el fin de alcanzar la solución de ésta”, a este concepto pensamos debería añadirse con la intervención de un facilitador.

La conciliación por su parte es conceptuada por el numeral 25 del multicitado ordenamiento como un "mecanismo voluntario mediante el cual los Intervinientes, en libre ejercicio de su autonomía, proponen opciones de solución a la controversia en que se encuentran involucrados"

La misma ley en el antedicho precepto establece la diferencia entra ambas figuras, la cual hace consistir en el tipo de intervención que realiza el facilitador, que en el caso de la conciliación es de carácter más activo al estar facultado para proponer soluciones viables en el caso concreto siempre bajo el estricto respeto a los principios que ya fueron enumerados con anterioridad. ${ }^{44}$.

Por otra parte, la denominada junta restaurativa es considerada por la ley como "el mecanismo mediante el cual la víctima u ofendido, el imputado y, en su caso, la comunidad afectada, en libre ejercicio de su autonomía, buscan, construyen y proponen opciones de solución a la controversia, con el objeto de lograr un Acuerdo que atienda las necesidades y responsabilidades individuales y colectivas, así como la

44 Ley Nacional de Mecanismos Alternativos de solución de controversias en materia Penal, óp. Cit., art. 26. 
reintegración de la víctima u ofendido y del imputado a la comunidad y la recomposición del tejido social". ${ }^{45}$

Esta última a diferencia de las dos anteriores, parte de propuestas de los mismos afectados quienes establecen ante el respectivo órgano sus prioridades para la restauración de su esfera jurídica violentada.

\section{Realidad mexicana en La materia PENAL}

La gestación de un importante proceso de creación legislativa alrededor de los mecanismos alternativos de solución de controversias en el mundo no fue ajeno al legislador mexicano y a la vera de la trascendente reforma constitucional en materia de derechos humanos, se va conformando la reforma sustancial al proceso penal, en cuya transformación va imbíbita la justicia alternativa como una herramienta fundamental que conforma esta evolución hacia un sistema que se busca sea más justo y que amplíe de manera visible la salvaguarda de los derechos humanos tanto del imputado como de la víctima.

Es así como se consagra constitucionalmente estos mecanismos en los términos ya apuntados y de ahí deriva la legislación ordinaria a la que igualmente hemos hechos alusión, de todo lo cual resulta el surgimiento de leyes estatales que buscan dar cumplimiento a la referida justicia alternativa bajo diferentes contextos y creando organismos estatales para tal fin.

Un punto importante es entonces, la creación de institutos ad hoc dependientes de los Tribunales Superiores de Justicia de las entidades federativas, insertamos a continuación una relación de las entidades federativas, la fecha de su creación y la denominación que utilizan:

- Aguascalientes: 22 de diciembre de 2004, Centro de Mediación y Conciliación

- Baja California: 19 de octubre de 2007, Centro estatal de Justicia Alternativa de Baja California

- Baja California Sur, 31 de julio de 2016 Centro Estatal de Justicia Alternativa de Baja California Sur.

45 Ibid., art. 27. 
- Campeche: 04 de diciembre de 2007, Centro de Justicia Alternativa

- Coahuila de Zaragoza: 22 de junio de 2005, entro de Medios Alternos de Solución de Controversias

- Ciudad de México: 11 de febrero de 2011 (antes Distrito Federal en el que se creó el 08 de enero de 2008), Centro de Justicia Alternativa del Tribunal Superior de Justicia de la Ciudad de México

- Chiapas: 18 de marzo de 2009, Centro estatal de Justicia Alternativa

- Chihuahua: septiembre de 2014, Instituto de Justicia Alternativa del Poder Judicial del Estado de Chihuahua

- Colima: 23 de septiembre de 2003, Centro estatal de Justicia Alternativa

- Durango: 18 de febrero de 2009, Centro Estatal de Justicia Alternativa

- Estado de México: 01 de enero de 2011, Centro estatal de Mediación, Conciliación y Justicia Restaurativa

- Guanajuato: 12 de septiembre de 2006, Centro estatal de Justicia Alternativa

- Guerrero: 16 de diciembre de 2016. Centro estatal de Mecanismos Alternativos de Solución de Controversias y Centro de Justicia Alternativa en materia penal

- Hidalgo: 21 de abril de 2008, Centro Estatal de Justicia Alternativa del Estado de Hidalgo

- Jalisco: 30 de enero de 2007, Instituto de Justicia Alternativa del estado de Jalisco

- Michoacán de Ocampo: 03 de marzo de 2005, Centro Estatal de Justicia Alternativa y Restaurativa

- Morelos: 18 de agosto de 2008, Centro de Justicia Alternativa

- Nayarit: Aprobada por el Congreso en abril de 2011, Centro Estatal de Justicia Alternativa y de Convivencia Familiar

- Nuevo León: 14 de enero de 2005, Centro Estatal de métodos alternos para la solución de controversias (hoy Instituto de 
Mecanismos Alternativos para la solución de controversias del Estado de Nuevo León.

- Oaxaca: 12 de abril de 2004, Centro de Justicia Alternativa.

- Puebla: 18 de diciembre de 2002, Centro estatal de Mediación del Tribunal Superior de Justicia del Estado de Puebla.

- Querétaro: 20 de junio de 2007, Centro de Mediación y Conciliación.

- Quintana Roo: 16 de diciembre de 2009, Centro de Justicia Alternativa.

- Sinaloa, 17 de octubre de 2016, Centro de Mecanismos Alternativos de Solución de Controversias en materia Familiar.

- Sonora: 07 de abril de 2008 Centro de Justicia Alternativa del Poder Judicial del Estado de Sonora (materias: civil, familiar y mercantil, penal intraprocesal).

- San Luis Potosí: 16 de octubre de 2012, Centro Estatal de Mediación y Conciliación.

- Tabasco: 29 de septiembre de 2012, Centro de Acceso a la Justicia Alternativa del Poder Judicial del Estado de Tabasco.

- Tamaulipas: 21 de agosto de 2007, Centro de Mecanismos Alternativos para la Solución de Conflictos.

- Tlaxcala: 13 de abril de 2007, Centro Estatal de Justicia Alternativa del Estado de Tlaxcala.

- Veracruz de Ignacio de la Llave: 15 de agosto de 2005, Centro Estatal de Justicia Alternativa de Veracruz.

- Yucatán: 24 de julio de 2009, Centro Estatal de Solución de Controversias del Estado.

- Zacatecas: 26 de diciembre de 2008, Centro Estatal de Justicia Alternativa (solo materia Civil, Familiar y Mercantil)

¿Cuál es la situación particular en materia penal en nuestro país? En este contexto vemos que además de las instituciones apuntadas, existen dependientes de las fiscalías o procuradurías generales de las entidades federativas órganos que apoyan la implementación de estos mecanismos exclusivamente para la materia penal, lo cual cabría preguntarse si duplica los costos, infraestructura y esfuerzos del estado o se justifica; 
así tenemos un estudio realizado por el Dr. Zepeda Leucona en el que en 2016 examina el quehacer de la justicia en materia penal bajo los auspicios de la organización Impunidad Cero, en el cual verifica las 32 entidades federativas del país y detecta severos problemas derivados de la insuficiencia de ministerios públicos y de la disminución de su eficacia pese a la paulatina implementación del nuevo sistema de justicia penal, cuestiones que a la par que las cifras negras demeritan la impartición de justicia en un alto grado.

En consecuencia, no hay un consenso a nivel nacional de la forma de implementar dichos centros o institutos y cada entidad federativa los crea acorde a lo que estima más adecuado eludiendo en ocasiones la complejidad de la materia penal; sin embargo, el 27 de agosto de 2016, la Comisión Nacional de Tribunales Superiores de Justicia de los Estados Unidos Mexicanos (CONATRIB) creó la "Red Nacional de Mecanismos Alternativos de solución de Controversias" mediante el acuerdo 1402/2016, estableciéndose como un medio de comunicación entre tales organismos, cuando menos aquellos que existen en el país en sedes jurisdiccionales, lo que estimamos a largo plazo permitirá alcanzar un alto grado de uniformidad en sus actuaciones y regulación que favorecerán a los justiciables.

Es evidente que la sola implementación de la legislación y los centros para la aplicación de tales mecanismos alternos no es per se la solución para todos los problemas de acceso a la justicia que afectan a la población mexicana, ello derivado de los altos índices de impunidad,

Al respecto Hernández Pliego ${ }^{46}$ hace énfasis en que:

La situación se agrava pues en el día a día, las víctimas del delito no son tratadas por la autoridad con respeto a su dignidad, no tienen verdadero acceso a la justicia, ni logran la reparación del daño a que tienen derecho, conforme a los prolijos catálogos descritos en las legislaciones referidas, sin dejar de considerar el agravio que se causa a la comunidad si no existe la denuncia, es decir, el 77\% constituye la cifra negra, los que no denuncian; bien, del $23 \%$ que denuncia solamente se consigna un $13 \%$; el $4 \%$ obtiene sentencia de condena y únicamente el $2 \%$ son condenados a reparar el daño.

\footnotetext{
${ }^{46}$ HERNÁNDEZ PLIEGO, Julio Antonio, óp. Cit., p. 345.
} 
Esto es palpable si atendemos a que según Zepeda Leucona ${ }^{47}$ : mientras que en el 2015 se iniciaron 791 mil 826 carpetas de investigación de competencia local en el país (Censo Nacional de Procuración de Justicia [CNPJ] 2016 del Instituto Nacional de Geografía y Estadística [INEGI]), apenas se iniciaron 50 mil 37 asuntos penales del sistema acusatorio ante los juzgados de control (Censo Nacional de Impartición de Justicia [CNIJ] 2016, INEGI). Es decir, sólo el 6.3\% de los asuntos ingresados a las procuradurías llegan a los jueces.

Lo cual nos lleva a concluir que si se eficientizan los mecanismos alternos muchos de esos casos que nunca salen de la fiscalía podrían acercar la justicia a muchos ciudadanos que a la fecha no la alcanzan por deficiencias de los propios órganos estatales o por su propia desconfianza en el sistema que los lleva a no denunciar engrosando las ya de por sí elevadas cifras negras.

El INEGI (Instituto Nacional de Información Estadística y Geográfica) a partir del 2008 crea el Subsistema Nacional de Información de Gobierno, Seguridad Pública e Impartición de Justicia (SNIGSPIJ) mediante acuerdo de la Junta de Gobierno del mencionado instituto y a propuesta de su Consejo Consultivo en los términos del artículo 15 de la ley que lo regula y con el objetivo específico de:

Institucionalizar y operar un esquema coordinado para la producción, integración, conservación y difusión de información estadística y geográfica de interés nacional, de calidad, pertinente, veraz y oportuna que permita conocer la situación que guardan la gestión y el desempeño de las instituciones públicas que conforman al Estado Mexicano y a sus respectivos poderes en las funciones de gobierno, seguridad pública e impartición de justicia, para apoyar los procesos de diseño, implementación, monitoreo y evaluación de las políticas públicas en estas materias ${ }^{48}$.

El subsistema arrojó en 2015 la siguiente información acerca de la justicia alternativa en México: se recibieron 164244 solicitudes, 150475 de ellas resultaron procedentes, y 13769 restantes fueron desechadas.

\footnotetext{
47 ZEPEDA LEUCONA, Guillermo Raúl, óp. Cit.

48

INEGI, Censo Nacional de Justicia Estatal 2016.
} 
En las solicitudes procedentes, el principal mecanismo empleado fue mediación en un 84.2 por ciento, seguido de la conciliación con el ocho por ciento. Para el resto de los mecanismos los porcentajes fueron inferiores al cinco por ciento. Asimismo, en lo que atañe al derecho penal, de estas cifras únicamente el 9.4 por ciento le corresponden. ${ }^{49}$

De lo anterior podemos colegir que, si bien el ministerio público como se dijo en párrafos antecedentes insta a las víctimas y ofendidos a celebrar este tipo de acuerdos, los resultados en la práctica aun dejan mucho que desear.

\section{Consideraciones finales}

Los mecanismos alternos de solución de controversias son indudablemente herramientas del sistema jurídico en México y parte integrante de la justicia alternativa, su eficacia en cuanto a la economía procesal y la descarga hacia los saturados tribunales del orden penal es indiscutible, en tanto que, como herramientas de acceso a la justicia su incidencia deberá juzgarse de manera más prudente y en estudios que examinen no la cantidad de asuntos resueltos como se realiza actualmente sino con base en indicadores cualitativos que nos evidencien verbigracia, el grado de satisfacción de las víctimas en ellos.

Es claro que los mecanismos alternos de solución de controversias resultan relevantes en el contexto del derecho penal actual, tan es así que el legislador mexicano no solo los regula dentro de legislación del ramo como lo es el Código Nacional de Procedimientos Penales, sino que consideró que su importancia bien valía una ley ex profeso como lo es la Ley Nacional de Mecanismos Alternativos de solución de controversias en materia Penal.

¿Qué tanto se justifica? Creemos que válidamente pudieron regularse en el Código Nacional de Procedimientos Penales, sin embargo, la normativización separada a nuestro juicio obedece tal vez a un afán del legislador de establecer su naturaleza extraprocesal.

49 Ibid., p. 40 
Los indicadores actuales no nos hablan-como ya se indicó- de eficacia cualitativa, sino de reducción de procesos lo que no necesariamente lleva aparejada una excelencia en el quehacer de la justicia alternativa, porque se deben tomar en consideración aspectos tan importantes como las cifras negras y la deficiente integración de los expedientes que llevan a los porcentajes analizados en anteriores apartados del presente estudio y que resultan vergonzantes a la luz del acceso a la justicia puesto que al parecer solo un $2 \%$ de las víctimas acceden a la reparación del daño, ello sin aspirar a que se trate de una reparación integral.

En consecuencia, la existencia de los mecanismos alternativos, cuando menos por lo que hace a la materia penal, hasta el momento no han evidenciado su impacto en la vulneración de los derechos de los ciudadanos y resultan excelentes de iure, pero aún no de facto.

Otro punto esencial en el que el estado mexicano debe centrar su atención, lo es en cuanto al seguimiento de los acuerdos y su debido cumplimiento que, actualmente no se encuentra debidamente regulado y en consecuencia no se puede garantizar el debido cumplimiento de los acuerdos alcanzados, ya que la propia redacción del artículo 17 en el texto constitucional determina únicamente de manera ocasional y facultativa la supervisión del juzgador.

\section{RefERENCIAS}

ALCALÁ-ZAMORA Y CASTILLO, Niceto. Proceso autocomposición y defensa: Contribución al estudio de los fines del proceso, 3a ed., México: UNAM, 2000.

CORTE INTERAMERICANA DE DERECHOS HUMANOS, Caso Loayza Tamayo vs Perú, Reparaciones y costas, Sentencia de 27 de noviembre de 1988, Serie C, No. 42, párr. 147.

CORTE INTERAMERICANA DE DERECHOS HUMANOS, Caso Myrna Mack Chang vs Guatemala, Fondo, reparaciones y costas, Sentencia de 25 de noviembre de 2003, Serie C, No. 101, párr. 268.

ESPARZA MARTÍNEZ, Bernardino. La reparación del daño. México: INACIPE, 2015. ESTAVILLO CASTRO, Fernando. Medios alternativos de solución de controversias. Jurídica, Anuario del Departamento de Derecho de la Universidad Iberoamericana, México, n. 26, pp. 373-406. 1996. 
GONZÁLEZ DE COSSÍO, Francisco. Mecanismos alternativos de solución de controversias: nota sobre el creciente desarrollo del área. Ars Iuris, n. 30, p. 39- 67, 2003. HERNÁNDEZ PLIEGO, Julio Antonio. La reparación del año en el CNPP. In: GARCÍA RAMÍREZ, Sergio; GONZÁLEZ MARISCAL, Olga (Coord.). El Código Nacional de Procedimientos Penales: Estudios. México: UNAM, 2015. pp. 239-254.

INEGI, Censo Nacional de Justicia Estatal 2016- Disponible en: < http://internet. contenidos.inegi.org.mx/contenidos/Productos/prod_serv/contenidos/espanol/ bvinegi/productos/nueva_estruc/702825091583.pdf>. Accedida en 12 dic. 2018.

LANDER, Adriana (Coord.). Las reformas al sistema de justicia penal en Japón y en América Latina, Logros, problemas, y perspectiva, Instituto Latinoamericano de las Naciones Unidas para la Prevención del Delito y el Tratamiento del Delincuente, Costa Rica: ILANUD, 2011.

LE CLERQ ORTEGA, Juan Antonio; RODRÍGUEZ SÁNCHEZ LARA, Gerardo (Coord.). La impunidad subnacional en México y sus dimensiones IGI MEX 2018. Puebla: Universidad de las Américas, 2018.

LILLO LOBOS, Ricardo; CABEZÓN PALOMINOS, Andrea; FANDIÑO CASTRO, Marco. Mecanismos alternativos al proceso judicial para favorecer el acceso a la justicia en América Latina. Disponível em: <http://www.bivica.org/upload/mecanismos-proceso-judicial.pdf>. Acesso em: 07 dic. 2018.

NANCLARES MÁRQUEZ, Juliana; GÓMEZ GÓMEZ, Ariel Humberto. La reparación: una aproximación a su historia, presente y prospectiva. Civilizar ciencias sociales y humanas. Bogotá, v. 17, n. 33, pp. 59-79, 2017.

NÓBREGA DE ABREU CAMPANÁRIO, Micaela Susana, "Mediação penal: Inserção de meios alternativos de resolução de conflito", Civitas, v. 13, n. 1 (2013), p. 118135. https://doi.org/10.15448/1984-7289.2013.1.12593

PALI, Brunilda. "Active justice: Restorative justice processes as fertile ground for exercising citizenship”, Sistema Penal \& Violência Revista Eletrônica da Faculdade de Direito. Rio Grande do Sul: v. 6, n. I, p. 31-42, janeiro-junho 2014.

VADO GRAJALES, Luis Octavio. Medios alternativos de solución de conflictos. In CIENFUEGOS, David y MACÍAS VÁSQUEZ María del Carmen (Coord.). Estudios en homenaje a Marcia Muñoz de Alba Medrano. México: UNAM, 2006.

VÁSQUEZ SANTAMARÍA, Jorge Eduardo; LEZCANO MIRANDA, Martha Eugenia. The alternative methods of conflict resolution: some improvement challenges for justice in Colombia. In: MOKRYS, Michal; BADURA, Stefan (editores). Proceedings in Human and Social Sciences at the Common Conference. Zilina: EDIS, 2017. 
VIVERO DE PORRAS, Carmen de. Medios alternativos de solución de conflictos. eXtoikos, n. 12, pp. 35-37, 2013.

XIV Cumbre Judicial Iberoamericana. Reglas de Brasilia sobre Acceso a la Justicia de las personas en condiciones de Vulnerabilidad, celebrada en Brasilia, del 4 al 6 de marzo de 2008.

ZEPEDA LEUCONA, Guillermo Raúl. Índice estatal de desempeño de las procuradurías y fiscalías. Disponível em: <https://www.impunidadcero.org/.../15_Impunidad_Cero_Ranking_de_procuradurias.pdf>. Acesso em: 12 dic. 2018.

\section{Informações adicionais e declarações dos autores (integridade científica)}

Declaração de conflito de interesses (conflict of interest declaration): a autora confirma que não há conflitos de interesse na realização das pesquisas expostas e na redação deste artigo.

Declaração de autoria e especificação das contribuições (declaration of authorship): todas e somente as pessoas que atendem os requisitos de autoria deste artigo estão listadas como autores; todos os coautores se responsabilizam integralmente por este trabalho em sua totalidade.

Declaração de ineditismo e originalidade (declaration of originality): a autora assegura que o texto aqui publicado não foi divulgado anteriormente em outro meio e que futura republicação somente se realizará com a indicação expressa da referência desta publicação original; também atesta que não há plágio de terceiros ou autoplágio. 


\section{Dados do processo editorial}

(http://www.ibraspp.com.br/revista/index.php/RBDPP/about/editorialPolicies)

- Recebido em: 22/12/2018

Equipe editorial envolvida

- Controle preliminar e verificação de plágio:

- Editor-chefe: 1 (VGV) 22/12/2018

- Avaliação 1: 27/12/2018

- Editor-associado: 1 (ELL)

- Avaliação 2: 13/01/2019

- Avaliação 3: 15/01/2019

- Decisão editorial preliminar: 20/01/2019

- Retorno rodada de correções: 05/02/2019

- Decisão editorial final: 08/02/2019

\section{COMO CITAR ESTE ARTIGO:}

COBOS CAMPOS, Amalia Patricia. Los mecanismos alternativos de solución de controversias en materia penal en México y su realidad. Revista Brasileira de Direito Processual Penal, Porto Alegre, vol. 5, n. 1, p. 115-144, jan./abr. 2019. https://doi.org/10.22197/rbdpp.v5i1.212

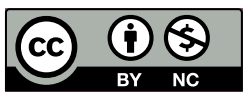

Esta obra está licenciada com uma Licença Creative Commons Atribuição-NãoComercial 4.0 Internacional. 